\title{
Serum Paraoxonase (Arylesterase) Activity in Chronic Renal Failure
}

\author{
BALASUBRAMANI AM GAYATHRI, ${ }^{1}$ ANAND USHA, ${ }^{2}$ DURAISAMY VIJ AYA ${ }^{3}$
}

\begin{abstract}
:
Background: Mortality rates are higher among patients with chronic renal failure with a good proportion of this excess burden being attributable to cardiovascular disease. This excess risk is not entirely explained by elevated traditional risk factors. Among the non-traditional risk factors, serum paraoxonase (Arylesterase) activity is an important one.

Materials and Methods: It was a case-control study which included total I 27 subjects, 44 were non-dialysis CKD patients, 33 Heamodialysis dependent patients and 50 healthy controls. HDL-C, Apo-A and serum paraoxonase (Arylesterase) activity was estimated and compared with normal control population.

Results: Serum Arylesterase activity, a measure of PON was significantly lower in CRF (on conservative management and on hemodialysis) compared to controls.

Conclusion: Measurement of anti oxidant capacity of HDL-C may improve the predictive accuracy of atherosclerotic coronary artery disease, providing new strategies for the prevention and treatment of accelerated atherosclerosis in chronic renal failure.
\end{abstract}

Keyword: Serum paraoxonase (Arylesterase), chronic renal failure, Atherosclerosis,

\section{Introduction}

Paraoxonase (aryldialkylphosphatase, EC 3.1.8.1) is a calcium dependent polymorphic enzyme with three activities, paraoxonase, arylesterase and dyazoxonase. ${ }^{1}$ It is widely distributed in liver, kidney, intestine and also in serum. In serum, paraoxonase (PON) circulates as a high density lipoprotein cholesterol (HDL-C) component, tightly bound with the hydrophobhic N-terminal domain to apo A1 of HDLC. Biochemical studies have shown that anti oxidant activity of HDL - C is shown to reside in its enzymes, particularly paraoxonase and hence a major contributor to its anti atherogenic role. $^{2}$

Oxidation of low density lipoprotein Cholesterol (LDL -C) plays a pivotal role in the early development of atherosclerosis. An increase in susceptibility for oxidation of LDL -C has been reported in chronic renal failure (CRF). ${ }^{3}$ Accelerated atherosclerosis and altered lipoprotein metabolism is responsible for increased cardiovascular events and cardiac death in chronic renal failure. ${ }^{4}$ Inverse correlation is shown between HDL - C concentration and the development of atherosclerosis. PON associated with HDL- $C$ is important in determining the capacity of HDL- C against oxidative modification and in turn to protect against atherosclerosis in chronic renal failure. ${ }^{5}$
Recently it has been reported that significant reduction of serum paraoxonase activity occurs in chronic renal failure, explaining the cause for high and premature incidence of atherosclerosis in these individuals. ${ }^{6}$ The phenotypic distribution of PON can be used to subdivide the population into three groups $\mathrm{AA}$ represents low, $\mathrm{AB}$ intermediate and BB high enzyme activity. ${ }^{7}$ Arylesterase activity is a measure of PON activity, in which p- nitro phenyl acetate is used as a substrate. The aim of this study was to measure serum PON - arylesterase activity and phenotypic distribution in patients with chronic renal failure (both on conservative management and on hemodialysis) and healthy individuals.

\section{Materials and Methods:}

\section{Subjects}

The study was carried out on 44 CRF (mean age-53,range 2473) patients on conservative management and on $33 \mathrm{CRF}$ patients on hemodialysis , 3 times/week for 4.5 hours 9 mean age -50 , range 24-72)and 50 healthy controls (mean age 43,range 26-69), in the department of Biochemistry , PSG IMSR , Coimbatore. Samples were collected from proved cases of CRF (patients having GFR $<30 \mathrm{~mL} / \mathrm{min}$ and serum creatinine $>1.6 \mathrm{mg} / \mathrm{dL}$ for more than three months, along with clinical and serological findings were considered having

1. Assistant Professor, Department of Biochemistry, PSG Institute of medical sciences and Research. Coimbatore, India

2. Professor, Department of Biochemistry, PSG Institute of medical sciences and Research. Coimbatore, India

3. Professor ,Department of Biochemistry, PSG Institute of medical sciences and Research .Coimbatore, India

Correspondence: Anand Usha, Professor, Department of Biochemistry, PSG Institute of medical sciences and Research. Coimbatore, India. 
CRF) maintained on conservative management and those on hemodialysis, from the department of nephrology, PSG Hospitals, Coimbatore.

The causes for CRF in patients with conservative management were diabetes mellitus -34\%, hypertension $32 \%$, chronic glomerulo nephritis - 20\%, other causes $-14 \%$ and on patients under going hemodialysis were diabetes mellitus $-40 \%$, hypertension $-36 \%$ and chronic glomerulo nephritis $-16 \%$ and other causes $-8 \%$.

No antioxidant medications were taken by the cases and all were on renal diet ( $50 \mathrm{~g}$ of protein and $5 \mathrm{~g}$ salt/day). The healthy controls were age and sex matched, were not on any kind of prescribed medications or dietary restrictions. The study was approved by the institutional ethical committee and informed consent was obtained from all the subjects.

\section{Biochemical Assay}

The blood samples were collected using commercially available (BD vacutainers) serum gel tubes under strict aseptic conditions from antecubital veins after an over night fast for 12 hours and before hemodialysis. For preparation of venous serum, the blood was allowed to clot for 30 minutes and after which the blood was centrifuged $3000 \mathrm{rpm}$ for 15 minutes and the clear serum was used for biochemical analysis.

\section{Lipid Measurement}

Levels of HDL -C, Apo-A were determined immediately in Roche Auto analyser (Immuno turbidimetric method) using dedicated kits. Levels of serum creatinine were determined Roche Auto analyser [Jaffe's Method] using dedicated kits. GFR was calculated by the modified diet and renal disease [MDRD] formula. The stages of chronic kidney disease were classified according to stages;

Stage 1 CKD

Slightly diminished function: Kidney damaged with or relatively high GFR [>90 mL/min/1.73mL]

Kidney damage is defined as pathologic abnormalities or markers of damage, including abnormalities in blood or urine test or imaging studies.

\section{Stage 2 CKD}

Mild reduction in GFR [60-89mL/min/1.73m²] with kidney damage. Kidney damage is defined as pathologic abnormalities or markers of damage, including abnormalities in blood or urine test or imaging studies.

\section{Stage 3 CKD}

Moderate reduction in GFR [30-59mL/min $\left./ 1.73 \mathrm{~m}^{2}\right]$

Stage 4 CKD

Severe reduction in GFR [15-29mL/min/1.73m²]
Stage 5 CKD

Kidney failure [GFR $<15 \mathrm{~mL} / \mathrm{min} / 1.73 \mathrm{~m}^{2}$ or permanent renal replacement therapy (RRT)]

\section{Serum PON assay -}

This enzyme was estimated spectrophotometrically using $5.5 \mathrm{mM}$ 4-nitrophenylacetate as the substrate in $20 \mathrm{mM}$ Tris-HCl buffer at a pH of 8.0. The increase in absorbance due to the formation of the yellow 4-nitro-phenol was monitored at $412 \mathrm{~nm}$ for three minutes. For each sample basal PON activity as well as salt-stimulated PON activity was determined as described below. ${ }^{6}$ Basal PON -This was estimated by using the Tris-HCl buffer containing only $1 \mathrm{mM}$ calcium chloride. Salt Stimulated PON - This was estimated by using the same Tris-HCl buffer which however contained $1 \mathrm{mM}$ calcium chloride as well as $1 \mathrm{M} \mathrm{NaCl}$. PON Activity was calculated after corrections were made for non-enzymatic hydrolysis. PON was taken to be $1 \mathrm{U} / \mathrm{L}$ when the rate of formation of the product 4-nitrophenol was $1 \mathrm{ìmol} /$ minute under the assay conditions.

Chemicals: - 4-nitrophenol acetate was procured from Sigma Chemical Company ( St. Louis, MO,USA). All other chemicals used for the assay of PON were of analytical grade.

\section{Paraoxonase Phenotype Distribution}

The Pearson stimulation of PON was calculated as

SALT STIMULATED PON ACTIVITYBASAL PON ACTIVITY

BASAL PON ACTIVITY $\quad$ X $100 \%$

Individuals were classified for PON phenotype using the antimode of PON as proposed by Eckerson et al. ${ }^{8}$ Individuals below the limit of $60 \%$ stimulation were considered AA phenotype, between 60-200\% AB phenotype, and above the level 200\% stimulation BB phenotype.

\section{Statistical Analysis}

The results were expressed as mean \pm standard deviation. $p$ value of $<0.05$ was considered statistically significant. Statistical analysis was performed using the statistical package for social sciences (SPSS 10). Student't' test was used to compare mean values. Pearson's Correlation coefficient analysis was used to find the degree of correlation between parameters.

\section{Results}

$51 \%$ of the CRF patients on conservative management belong to stage 5 chronic kidney disease. The remaining 30\% patients fall into stage $4 \mathrm{CKD}, 14 \%$ of the patients in stage 2 and $5 \%$ of patients in stage $1 \mathrm{CKD}$.

Serum Arylesterase activity a measure of PON was significantly lower $(\mathrm{p}<0.05)$ in CRF (on conservative 
management and on hemodialysis) compared to controls. (Table-I)

\section{Paraoxonase Phenotype distribution}

In patients with chronic renal failure, both on conservative management and on hemodialysis 43, 30 subjects belong to AA Phenotype (low Paraoxonase activity) respectively. This explains the cause for accelerated atherosclerosis in chronic renal failure. In the control group, 17 belong to AA Phenotype which also adds to the cause for increased incidence of atherosclerosis in the general population

\section{Lipid Parameters}

HDL- C concentration was significantly lower in the CRF patients on conservative management and on hemodialysis $(\mathrm{p}<0.05$ ) compared to the control group.

Apo A concentrations was significantly lower in the CRF patients on conservative management and on hemodialysis $(\mathrm{p}<0.005)$ compared to the control group

HDL standardized Paraoxonase activity

Since HDL-C concentrations and Arylesterase enzyme activity were lower in CRF patients, arylesterase activity was standardized for HDL cholesterol concentrations. It was found that HDL Standardized arylesterase activity was significantly reduced in the CRF patients than in the control subjects.

Table-I

\begin{tabular}{|c|c|c|}
\hline Parameter & mean \pm SD & P value* \\
\hline \multicolumn{3}{|l|}{ Basal arylesterase activity (U/L) } \\
\hline Control & $114.35 \pm 35.68$ & \\
\hline CRF on conservative Management & $89.27 \pm 20.64$ & $0.003 * *$ \\
\hline CRF on Hemodialysis & $39.05 \pm 10.35$ & $0.001 * *$ \\
\hline \multicolumn{3}{|c|}{ Salt Stimulated arylesterase activity(U/L) } \\
\hline Control & $137.5 \pm 45.29$ & \\
\hline CRF on conservative Management & $103.4 \pm 26.34$ & $0.006 * *$ \\
\hline CRF on Hemodialysis & $122.3 \pm 36.10$ & $0.033 * *$ \\
\hline \multicolumn{3}{|l|}{ HDL Cholesterol } \\
\hline Control & $52.97 \pm 35.87$ & \\
\hline CRF on conservative Management & $34.60 \pm 12.83$ & $0.005^{* *}$ \\
\hline CRF on Hemodialysis & $29.89 \pm 11.20$ & $0.001 * *$ \\
\hline Apo A Control & $151.30 \pm 51.89$ & \\
\hline CRF on conservative Management & $110.58 \pm 29.83$ & $0.05 * *$ \\
\hline CRF on Hemodialysis & $83.66 \pm 32.76$ & $0.03 * *$ \\
\hline \multicolumn{3}{|l|}{ Basal Arylesterase/HDL - C ratio } \\
\hline Control & $2.54 \pm 1.00$ & \\
\hline CRF on conservative Management & $3.20 \pm 2.46$ & $0.001 * *$ \\
\hline CRF on Hemodialysis & $4.59 \pm 3.27$ & $0.002 * *$ \\
\hline \multicolumn{3}{|c|}{ Salt Stimulated Arylesterase/HDL -C ratio } \\
\hline Control & $3.05 \pm 1.28$ & \\
\hline CRF on conservative Management & $3.73 \pm 3.02$ & $0.047 * *$ \\
\hline CRF on Hemodialysis & $5.19 \pm 3.49$ & $0.002 * *$ \\
\hline
\end{tabular}

* Student t test, ** Significant

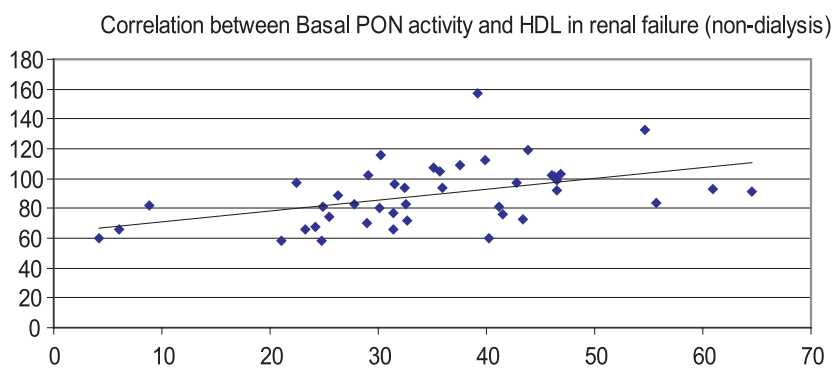

Fig.-1: Correlation between Basal PON activity and HDL in renal failure (non-dialysis)

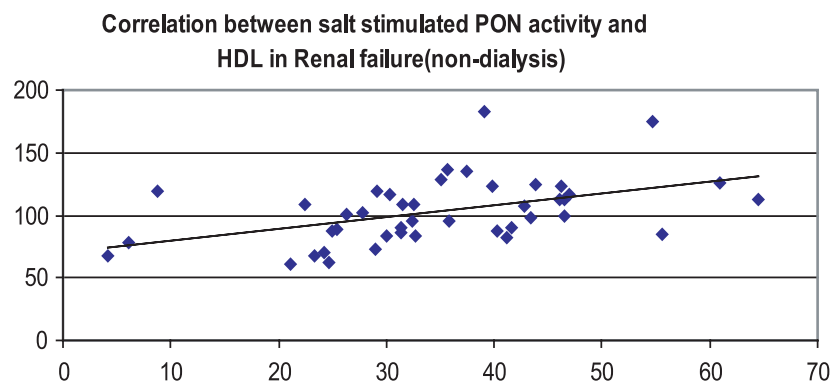

Fig.-2: Correlation between salt stimulated PON activity and HDL in Renal failure(non-dialysis)

\section{Discussion}

Chronic Renal failure is accompanied by a complex pattern of altered lipoprotein metabolism and structure. The key changes include oxidative modification of LDL-C, which accelerates the development and progression of atherosclerosis. ${ }^{9}$ It was well established that HDL-C protects against LDL-C induced oxidative modification and thereby prevents progression of atherosclerosis. The anti oxidant capacity of HDL-C depends on the enzymes associated with it, particularly PON. ${ }^{10}$

Our current findings have shown that serum arylesterase activity was lower in CRF (both on conservative management and on hemodialysis) than in the control group ( $p<0.01)$. In addition, the serum levels of HDL-C and Apo A were also lower in CRF group than in the control group ( $p<0.05)$. Low concentrations of HDL-C, Apo A and Arylesterase activity increase the susceptibility of LDL-C against oxidative modification and consequently atherosclerotic coronary heart disease. ${ }^{11,12}$

HDL -C standardized enzyme activities (HDL-C/PON Arylesterase activity) were lower in CRF, p $<0.05$ (Both on conservative management and on hemodialysis) (Table I). Similarly a significant positive correlation was determined between serum Basal PON activity, salt stimulated PON activity and HDL-C, Apo A levels in the CRF group on conservative management $(p<0.01)$ fig 1,2 . These data 
suggest that PON activity changes are not entirely dependent on HDL-C concentration in the CRF patients. ${ }^{13}$

During renal failure, the accumulation of nitrogen derived products could decrease the paraoxonase activity by modifying the synthesis or secretion or by directly inhibiting the enzyme. ${ }^{10}$ A reduction in serum PON activity as seen in the study, may increase the oxidative stress and makes not only LDL-C susceptible to oxidation but all other serum lipids, including HDL-C. HDL-C oxidation may impair its ability to induce cellular cholesterol efflux from macrophages. Hence, rather than the absolute levels of HDL-C, the quality of HDL$\mathrm{C}$ is maintained by its protective enzymes eg. $\mathrm{PON}$ is altered in chronic renal failure. ${ }^{14,15,16}$

Our study demonstrated that majority of the patients in the CRF group belong to AA phenotype which has a lower paraoxonase activity. This may be an important reason for the increasing incidence of atherosclerotic coronary artery disease in the population.

\section{Conclusion}

The serum HDL-C level does not reflect and assess HDL functional property. Even with a normal level of HDL-C, a measure of anti oxidant capacity of HDL-C will yield additional information, which improves the predictive accuracy of atherosclerotic coronary artery disease in chronic renal failure. It may also provide new strategies for the prevention and treatment of accelerated atherosclerosis in chronic renal failure.

\section{Conflict of Interest: None}

\section{References}

1. Mackness B, Durrington PN, Mackness MI. Human serum paraoxonase. Gen Pharmacol 1998; 31: 329-336

2. Mackness MI, Durrington PN. HDL, its enzymes and its potential to influence lipid peroxidation. Atherosclerosis 1995; 115: 243-53

3. Saeed SA, Elsharkawy M, Elsaeed K, Fooda O. Paraoxonase-1 (PON1) activity as a risk factor for atherosclerosis in chronic renal failure patients. Hemodial Int 2008; 12(4): 471-9

4. Daniel E. Weiner, Hocine Tighiouart, Manish G. Amin et al. Chronic Kidney Disease as a Risk Factor for Cardiovascular Disease and All-Cause Mortality: A Pooled Analysis of Community-Based Studies. J Am Soc Nephrol 2004; 15: 1307-1315
5. Alan S. Go, Glenn M. Chertow, Dongjie Fan, Charles E. McCulloch, and Chi-yuan Hsu. Chronic Kidney Disease and the Risks of Death,Cardiovascular Events, and Hospitalization.. N Engl J Med 2004; 351:1296-305

6. Paragh G, Asztalos L, Seres I, et al. Serum paraoxonase activity changes in uremic and kidney-transplanted patients. Nephron 1999; 83(2):126-31

7. Dubravka Juretiæ, Milena Tadijanoviæ, Branka Rekiæ, Vera Simeon-Rudolf, Elsa Reiner, Martin Barièiæ . Serum Paraoxonase Activities in Hemodialyzed Uremic Patients: Cohort Study. CMJ 2001; 42: 146-150

8. Eckerson HW, Romson J, Wyte C, La Du BN. The human serum paraoxonase polymorphism: identification of phenotypes by their response to salts. Am J Hum Genet. 1983; 35(2):214-227

9. Thomas Quaschning, Vera Krane, Thomas Metzger, and Christoph Wanner. Abnormalities in Uremic Lipoprotein Metabolism and Its Impact on Cardiovascular Disease. Am J Kidney Dis 2001; 38 (4), 1: S14-S19

10. Thierry F. Dantoine, Jean Debord, Jean -Pierre Charmes, et al. Decrease of Serum Paraoxonase Activity in Chronic Renal Failure. J Am Soc Nephrol 1998; 9: 2082-2088

11. Paragh G, Sers I, Balogh Z, Varga Z, Kârpâti I, Mâtyus J, et al. The serum paraoxonase activity patients with chronic renal failure and hyperlipidemia. Nephron 1998; 80:166170

12. Witztum JL, Daniel S. Role of oxidized low density lipoprotein in atherogenesis. J Clin Invest 1995; 88:17851792

13. Emin T Elkiran, Nefsal Mar, Bilge Aygen, Ferit Gursu, Aziz Karaoglu ,Suleyman Koca . Serum paraoxonase and arylesterase activities in patients with lung cancer in a Turkish population. BMC Cancer 2007; 7: 48

14. Aviram M, Rosenblat M, Bisgaier CL, Newton RS,PrimoParmo SL, La Du BN: Paraoxonase inhibits highdensity lipoprotein oxidation and preserves its functions. A possible peroxidative role for paraoxonase. J Clin Invest 1998; 101: 1581-1590

15. Morena M, Cristol JP, Dantoine T, Carbonneau MA, Descomps B, Canaud B: Protective effects of high-density lipoprotein against oxidative stress are impaired in haemodialysis patients. Nephrol Dial Transplant 2000; 15: 389-395

16. Suguru Yamamoto, Valentina Kon. Mechanisms for increased cardiovascular disease in chronic kidney dysfunction. Curr Opin Nephrol Hypertens. 2009; 18(3): 181-188 